\title{
Anticancer Medicinal Plants: Opportunities and Challenges For Conservation and Sustainable Use
}

\section{Rajeev Kumar*}

Department of Chemistry, Manav Rachna International Institute of Research Studies, Sector-43, Surajkund Road, Faridabad, Haryana, India

Keywords: Cancer, Plant extract

\section{Abstract}

As per the World Health Organization (WHO), more than $80 \%$ of the world's people depend on medicinal plants for their primary care. India has more than eight percent plant genetic diversity of the world's biodiversity with medicinal properties. Cancer is one of the foremost causes of death throughout the world. Naturopathy i.e., the use of plant extract or their derived products may reduce adverse side effects in the treatment of cancer. Recent research data shows that a lot of plants have promising anti-cancer properties but yet to be evaluated for human beings in the lab. The aim of this paper review is to identify the plants having anticancer properties, their conservation, sustainable use and challenges regarding their use as medicine.

used as medicine, insecticides, herbicides, preservatives, pigments, flavor, perfumes and spices. The risk of extinction of medicinal plant species has been increased from the last few decades. Regular destruction of habitat for construction purposes, increasing population and lack of knowledge are the main factors to accelerate the loss of species, especially in developing countries. Food and agricultural organization (FAO) stated that around $60 \%$ of the population totally depends upon the medicinal plants for their health care purpose. As per the guidelines of the European Commission, more than $80 \%$ of medicinal plants are disturbed by the human population and their unwanted activities such as pollution, overexploitation, and deforestation (GIPC, 2000). More and more drugs are extracted from plants in the tropical forest, only a few extracts are focused on more studies. Asimina triloba, Taxus brevifolia and Podophyllum peltatum plant-derived drugs are extracted from the forest of North American having high antitumor activity against ovarian, testicular and lymphoma lung cancer, respectively. These drugs are entered into the market for cancer treatments. These valuable resources are highly protected by various Government agencies. The conservation and sustainable use of plant species for the medical purpose has been studied widely by many research communities (Kumar et al., 2017). A lot of recommendations have been published for the conservation and sustainable use of plant species. Today medicinal plants are facing extinction or severe loss from the natural habitat. Thus, there is more and more requirement to preserve and conserve the medicinal plants increasing the quality and quantity of plant spec worldwide. Active substances of plant extracts are widely

*Corresponding Author: rajeevkumar.fet@mriu.edu.in 
for future pharmacological demands.

This article is divided into three parts to explain the anti-cancer properties of plants and their opportunities and challenges for conservation and sustainable use.

A. Identification of anticancer medicinal plants

B. Opportunities of medicinal plants sector

C. Challenges for conservation and sustainable use

\section{Identification of anticancer medicinal} plants:

Distribution of medicinal plants and their use is not uniform worldwide. India, China, Colombia, South Africa, and the United States have the highest variety of medicinal plants. More than 1000 plants are used as medicinal plants for the treatment of diseases without any cultivation in Europe. Leptadenia reticulate, Saussurea involucrate, Gymnema sylvestr, Caralluma bhupenderian, Zeyheria montan, Psoralea corylifoli, Gloriosa superba Antivenom, Nilgirianthus ciliates, Swertia chirayita, Achillea wilhelmsii, and Zufaee thyme are the main endangered species widely used for treatment of anticancer as well as anti-tumor, antimicrobial, antifungal, antioxidant and anti-aging (Kumar et al., 2017; Kooti et al., 2017).

Gymnema sylvestre (Asclepiadaceae family) genus is found in India, China, Malaysia, and Sri Lanka. This plant extract showed various pharmaceutical activities. Most of the species of this family showed antimicrobial, anti-hypercholesterol, hepatoprotective, antidiabetic and anticancer activity. Leptadenia reticulate (Asclepiadaceae family) commonly known as Swarna-Jivanti to give life or strength. It shows various biological activities such as antitumor, antimicrobial, and anticancer. It is also used for the treatment of fever, inflammation, tuberculosis, cough, dyspnoea, night blindness. Saussurea involucrate (Asteraceae family) is a Chinese plant. It is widely used to cure rheumatoid arthritis, inflammation, and gynopathy. L.reticulata species showed immune modulator, antiaging, and anticancer properties. Caralluma bhupenderiana (Apocynaceae family) is found in southern India and showed antimicrobial, antioxidant, and anticancer properties. Zeyheria montana (Bignoniaceae family) is found in Brazil. It contains lapachol, ß-lapachone, ursolic acid, and oleanoic acid and showed antimicrobial, antioxidant, and anticancer properties. Psoralea corylifolia (Fabaceae family) is found in tropical regions of the world. It is widely used in the treatment of diseases such as stomach pain, anti-helmintic, diuretics, and diabetes. Species P.corylifolia contains coumarins, isopsoralen, psoralen and angelicin, which showed antifungal, antioxidant, antibacterial, and antitumor activities. Gloriosa superba (Liliaceae family) is commonly known as Glory lily, found in Africa and Asia. It is widely used in the treatment of bleeding piles, arthritis, skin diseases, ulcers, snake bites etc. Swertia chirayita (Gentianaceae family) is found in Himalayan region. It is used as an anti- inflammatory, antihelmintic, liver booster, blood purifier, and antimalarial. S.chirayita contains xanthone, amarogentin, C-glucoside, xanthones, swertiamarin, mangiferin, iridoids, flavonoids, glycosides, swertiamarin, and secoiridoid showed various pharmacological activities. Nilgirianthus ciliatusis (Family Acanthaceae) found in southern Western Ghats, India. It contains various bioactive compounds such as stigmasterol, betulin, stigmasterol, lupeol, taraxerol, and glycoside showed pharmacological activities. Achillea wilhelmsii (Family Asteraceae; compositaea genus) is found in Iran. The essence of leaves and alcohol extracts has cyto-toxic effects on colon cancer cells. Zufaee thyme (Labiaceae family) plant grows preferably in tropical regions. Alcoholic extract hascyto-toxic effects on lung cancer cells.

\section{Opportunities of medicinal plants sector:}

As per the report of the World Health Organization (WHO) annually more than 14 billion US dollars medicinal plants are required to cure diseases worldwide which is increasing at a rate of 20 to $30 \%$ annually. It is more than ibillion US dollars annually only in India. The use of ayurvedic or herbal products is increased twice in the last few years. The United States, India, and China have a heterogeneous diversity of medicinal plants for the development of ayurvedic or herbal industries. This heterogeneous diversity of medicinal plants is helpful for future research in the medical field and explores their other values. Heterogeneous diversity of medicinal plants is also helpful to provide low-cost drugs in the market.

\section{Challenges in conservation \& sustainable use:}

Increasing the human population is leading to the continuous degradation of the forest and its products. It is very challenging to meet the necessities as well as to conserve the medicinal biodiversity. Increasing demand for medicinal plant species has led to the loss of their existing populations. Taxus baccata (Himalayan new species) is used to cure ovarian cancer. The high amount of its extract taxol has been gathered from the wild. Moreover, Dactylorhiza hatagirea, Polygonatum verticillatum, Aconitum heterophyllum, Nardostachys grandiflora, Megacarpoea polyandra, Gloriosa superba, and Arnebia benthamii species have been over-exploited for treatment in India. They have been placed in rare and endangered categories because of overexploitation. Leptadenia reticulate, Saussurea involucrate, Gymnema sylvestr, Caralluma bhupenderian, Zeyheria montan, Psoralea corylifoli, Gloriosa superba Antivenom, Nilgirianthus ciliates, Swertia chirayita, Achillea wilhelmsii, and Zufaee thyme are used to cure more than one disease, known as under pressure species. Over-exploitation of these species is not only affected their availability but also the loss of genetic diversity.

There are two main methods for the conservation of all 
types of plant species in-situ (conservation inside the native habitat) and ex-situ (conservation outside the native habitat). In-situ conservation is a very convenient and cheap method that offered conservation of a large number of organisms. However, ex-situ conservation is important for the breeding of endangered plant species under controlled conditions (Chen et al., 2016). Some important conservation techniques are shown in the schematic diagram.

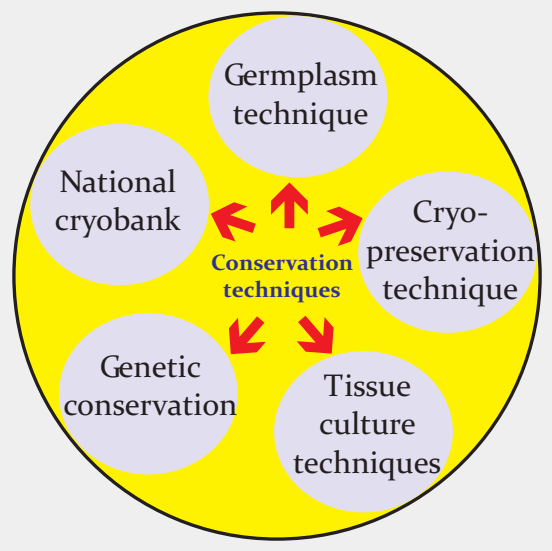

Figure-1: Schematic diagram for conservation of plants

Modern technologies have been developed to produce a large number of plant products to reduce the burden on natural habitat and fulfill the requirement of pharmaceutical industries. Suspension culture, secondary metabolites, synthetic seeds and development of transgenic plants, are the main in vitro regeneration system which helps to produce disease-free plants. These techniques have genetic integrity, shorter low term storability with an active regenerative ability (Raina et al., 2011). The sustainable use of these plants may be done by the replacement of root and main stem to leaves, buds or flowers. A lot of research is required to adopt the sustainable use of these plants (Ullah, 2017; Mahmoud \& Gairola, 2013).

Conclusively, a lot of recommendations and guidelines have been published for the conservation and sustainable use of medicinal plants, but a small portion of medicinal plant species conserved and sustainably used. A lot of efforts are required to initiate and support for conservation of medicinal plants for health care. Government and other non-governmental organizations promote in-situ conservation and sustainable uses of medicinal plants for global significance. It also promotes suspension culture, secondary metabolites, synthetic seeds and development of transgenic plants, which helps to produce disease-free plants. These techniques have genetic integrity, shorter low term storability with active regenerative ability.

\section{References:}

Chanchal, D.K., Alok, S., Rashi, S., Bijauliya, R.K., Yadav, R.D., \& Sabharwal, M. (2018): Various medicinal plants used in the treatment of anticancer activity. Int.J. Pharma. Sci. Res., 9(4): 1424-1429.

Chen, S.L., Yu, H., Luo, H.M., Wu, Q., Li, C.F., \& Steinmetz, A, (2016): Conservation and sustainable useof medicinal plants: problems, progress, and prospects. Chin. Med., 11-37.

GIPC (Government of India Planning Commission) (2000): Report of the task force on conservation \& sustainable use of medicinal plants. Pub. by: Government of India, Planning Commission. P 175 .

Greenwell, M., \& Rahman, P.K.S.M. (2015): Medicinal plants: their use in anticancer treatment. Int.J. Pharma. Sci. Res., 6(10): 41034112.

Kooti, W., Servatyari, K., Behzadifar, M., Asadi-Samani, M., Sadeghi, F., Nouri, B., \& Marzouni, H.Z, (2017): Effective medicinal plant in cancer treatment, Part 2: Review study. $L$. Evid. Based Comple. Altern. Med., 22(4):982-995.

Kumar, R., Krishnan, R., Priya, R., Samy, P., Lakkakula, S., Subramani, P., Rency, S., Arockiam, \& Manikandan, R. (2017): In vitro propagation and conservation of useful endangered medicinal plants with anticancer activity. $L$. Mole. Bio. Biotech., 2(3:8): 1-8.

Mahmoud, T. \& Gairola, S. (2013): Traditional knowledge and use of medicinal plants in theEastern Desert of Egypt: a case study from Wadi El-Gemal national park.J. Med. Plants Stud., $1(6): 10-17$.

Raina, R., Chand, R. \& Sharma, Y.P. (2011): Conservation strategies of some important medicinal plants. Int. J. Med. Arom. Plants, 1(3):342-347.

Ullah, N. (2017): Medicinal plants of Pakistan: Challenges and opportunities. J. Evid. Based Comple. Altern. Med., 6(4):1-3. 